\title{
Métodos Participativos no Planejamento Ambiental no Contexto de Ocupações Informais: Possibilidades e Limitações ${ }^{1}$
}

\author{
Andrea Zellhuber \\ Doutora em Planejamento Ambiental \\ Technische Universität München \\ Arcisstrabe, 21 - 80333 - München - Germany \\ zellhube@wzw.tum.de
}

\section{Resumo}

O presente trabalho fornece uma introdução aos conceitos teóricos de participação em planejamento ambiental e manejo de conservação da natureza. Através de um amplo estudo bibliográfico, se conseguiu resumir os principais critérios para a avaliação de processos participativos. Baseados nestes critérios se demonstra, através de um estudo de caso, quais as limitações e possibilidades de instrumentos participativos para gerenciar conflitos sócioambientais relacionados ao espaço urbano. Trata-se de um processo de planejamento participativo na periferia de Porto Alegre que visa a atualização do plano diretor de um bairro em cooperação com a população atingida. A avaliação deste projeto sustenta a argumentação de que processos participativos podem contribuir substancialmente para a democratização do planejamento urbano. Mas, ao mesmo tempo, ficou claro que não se pode acreditar que a participação da população seja a panacéia para a gestão urbano-ambiental.

Palavras-chave: Planejamento Ambiental. Métodos Participativos. Ocupações Informais.

\begin{abstract}
This paper provides an introduction to theoretical concepts of participation in environmental planning and handling of nature conservation. Through an extensive bibliographic research is able to summarize the main criteria for the evaluation of participatory processes. Based on these criteria is demonstrated, through a case study, what the limitations and possibilities of participatory tools to manage social and environmental conflicts related to urban space. This is a participatory planning process on the outskirts of Porto Alegre which aims to update the master plan for a district in cooperation with the affected population. The evaluation of this project supports the argument that participatory processes can contribute significantly to the democratization of urban planning. But, at the same time, it became clear that we can not believe that popular participation is a panacea for urban-environmental management.
\end{abstract}

Key-words: Environmental Planning. Participatory Methods. Informal Occupations.

\section{Introdução}

Como na maioria das metrópoles latino-americanas, a periferia de Porto Alegre (Rio Grande do Sul) se caracteriza por uma urbanização descontrolada e uma estrutura urbana fragmentada, composta por ocupações e loteamentos irregulares.

A urbanização desordenada na periferia de Porto Alegre resulta, sobretudo, de processos de migração intra-urbana, da segregação sócio-espacial devido à estrutura do Artigo submetido em 23 de junho de 2007 e aceito em 28 de julho de 2008 pelo Editor José Ricardo Maia de Siqueira, após double blind review. 
mercado imobiliário e de políticas urbanas fracassadas. Do ponto de vista do planejamento ambiental, a fragmentação urbana periférica leva a conflitos ambientais, pois as ocupações informais se concentram nas áreas ecologicamente mais sensíveis, que não têm valor no mercado imobiliário. Isto se reflete, principalmente, no processo acelerado de ocupação da cadeia de morros que circunda o espaço urbanizado e que se caracteriza por um mosaico de florestas subtropicais e campos ricos em espécies endêmicas.

Apesar de uma tendência progressista na política urbana de Porto Alegre, os instrumentos políticos falham ao não conseguir interferir nestes conflitos ambientais relacionados ao uso da terra. Analisando-se como as políticas urbanas e ambientais da administração local respondem à cidade informal da periferia, vêem-se claramente as contradições na atuação das instituições governamentais.

Tendo em vista a situação de conflito existente entre a expansão urbana e a preservação dos ambientes naturais na periferia de Porto Alegre, a implementação efetiva de políticas de conservação é um grande desafio. Num contexto em que medidas restritivas não funcionam, instrumentos cooperativas são apontados como alternativas para viabilizar a gestão urbana na cidade informal e, ainda, no contexto internacional de conservação da natureza, durante os últimos 20 anos, as abordagens de manejo cooperativo progressivamente ganharam importância como alternativa para os procedimentos comuns de cima para baixo (top down) nas políticas de conservação.

\section{Metodologia Adotada}

Metodologicamente, o presente trabalho se baseia em um estudo de caso extenso sobre um projeto de planejamento urbano participativo na periferia de Porto Alegre. Através de métodos de pesquisa social qualitativa, investigaram-se primeiramente os conflitos ambientais urbanos relacionados à urbanização desordenada no bairro Lomba do Pinheiro. Baseado nesta análise, em segundo lugar foi examinada em detalhe a integração destes problemas ambientais em processos cooperativos de planejamento. No estudo de caso foram aplicados principalmente os métodos de observação participante e entrevistas semi-estruturadas. Foram desenvolvidas entrevistas com os participantes do projeto de planejamento participativo, sendo o roteiro de perguntas baseado em critérios teóricos de participação. A autora acompanhou o projeto por um meio ano entre agosto 2002 e março 2003, voltando mais uma vez no final de 2004 para comparar os dados levantados com novas entrevistas num estágio avançado do projeto.

\section{Os Conceitos de Participação e Fundamentos Teóricos para a Avaliação de Processos Participativos}

Em geral, participação engloba todas as formas de engajamento da população em processos de tomada de decisão e ação que permite aos cidadãos influenciar a elaboração de políticas públicas e exercer controle sobre as ações do governo (Gaventa \& Valderrama 1999). Isto significa o direito a eleições livres e democráticas de representantes locais bem como direito a mecanismos participativos como plebiscito ou referendo, através de iniciativa popular e acesso às audiências públicas e debates (Saule Jr. et al. 2002). Estes mecanismos de participação direta nos processos de tomada de decisão são fortemente enfatizados na constituição brasileira assim como em várias leis federais (por exemplo: conselhos municipais estabelecidos para as áreas de saúde, educação, assistência social, crianças e jovens, meio ambiente e habitação). Como o enfoque do presente artigo é a participação em processos de 
decisão com respeito à conservação da natureza e planejamento ambiental, a seguir se entra em detalhe somente nesta questão específica.

Nas últimas décadas dentro do debate internacional de conservação da natureza, ocorreu uma mudança significativa em direção as assim chamadas estratégias de inclusão de pessoas ("people included") ou estratégias baseadas em comunidades ("community-based"). Essas novas formas de gestão estão sendo aplicadas, especialmente, em áreas que permitem uso sustentável, mas também, progressivamente em áreas com status de conservação mais restritivo. Para as últimas, a ênfase é colocada nos projetos integrando conservação com desenvolvimento local nas zonas de amortecimento, que são desenhados para minimizar o impacto na unidade de conservação e promover o desenvolvimento local dos arredores (Mannigel 2004; Stoll-Kleemann \& O'Riordan 2002; Mahanty \& Russel 2002).

Financiadoras e ONGs internacionais (e.g WWF e IUCN) progressivamente exigem a participação de stakeholders nos projetos de conservação. Um exemplo é o programa Global Environment Facility (GEF), que é um programa ambiental global financiado pelo Banco Mundial, que fortemente destaca participação local em projetos de conservação da biodiversidade como condição de financiamento (Stoll-Kleemann \& O'Riordan 2002). Em geral se reivindica que proteção da biodiversidade dependa para sua continuidade, em grande parte, de um manejo local com sensibilidade, em consonância com o artigo 10 da Convenção da Biodiversidade (CBD) (Stoll-Kleemann \& O'Riordan 2002; Borrini-Feyerabend 1996; McNeely 1995; Pimbert \& Pretty 1997). Essas estratégias de inclusão dos moradores locais visam uma relação cooperativa entre integridade de ecossistemas e subsistência da população local. A inclusão de interesses locais hoje em dia é considerada de fundamental importância para o manejo sustentável da biodiversidade (McNeely 1995). Fala-se muito em manejo cooperativo de áreas protegidas; isto implica que o órgão responsável pela unidade de conservação desenvolva uma parceria com outros stakeholder relevantes, sobretudo moradores locais e usuários de recursos. Assim, as instituições governamentais dividem suas responsabilidades no que diz respeito à unidade de conservação (Borrini-Feyerabend 1996). Espera-se, assim, fomentar o compromisso para a preservação da natureza por parte dos atores locais.

As abordagens cooperativas são estratégicas, especialmente onde a implementação de manejo efetivo das áreas protegidas é muito limitada em função da falta de recursos financeiros, de funcionários qualificados, de planos de manejos executáveis e também da falta de respaldo institucional por parte dos órgãos públicos. Estes esperam superar, pelo menos em parte, as limitações de monitoramento e fiscalização decorrentes de problemas financeiros crônicos através da transferência de responsabilidades na área protegida para os atores locais. Como os instrumentos meramente restritivos se mostraram difíceis para implementação, estratégias cooperativas estão sendo consideradas alternativas promissoras.

As políticas brasileiras de unidades de conservação refletem as mudanças das políticas internacionais de conservação. A lei federal $n^{\circ}$ 9.985/2000, que regulamenta o Sistema Nacional de Unidades de Conservação (SNUC), providencia um sistema amplo de categorias que incluem instrumentos inovadores de participação da população (Mannigel 2004, 22). Essa lei garante consultas públicas, criação de comitês de gestão e de co-gestão com ONGs. Os níveis de envolvimento da população previstos nela dependem dos objetivos e usos definidos para as respectivas categorias de unidade de conservação (Mannigel 2004, 22). Mesmo assim, a realidade ainda está longe destas proposições legais.

Também dentro da teoria de planejamento nos últimos vinte anos, houve uma mudança de conceitos (Souza 2003, 194). Cada vez mais se leva em conta a construção social do conhecimento. O novo conceito de planejamento se integra com os termos de planejamento cooperativo. Um princípio central destes processos de planejamento é procurar um equilíbrio entre o fundamento político e científico de uma tomada de decisão. Procura-se 
envolver de forma interativa os stakeholders locais nos processos de planejamento, decisão e implementação, levando em conta as várias dimensões da realidade. Além de métodos formais e científicos, se aplicam ferramentas de visualização e métodos narrativas. Como instrumentos mais conhecidos se pode citar os métodos de diagnósticos participativos. Com uma metodologia definida, técnicas de visualização e de trabalho de grupo, estes diagnósticos estimulam processos de aprendizagem coletiva. As técnicas mais comuns são discussões em grupo, mapeamentos em campo (mapas falantes), entrevistas, resgates de história e diagramas institucionais. O foco está no aprendizado cumulativo e na inclusão das perspectivas diferentes. Os especialistas e técnicos se restringem ao papel de moderador e facilitador. Rejeita-se a dominância do conhecimento científico em processos de tomada de decisão em prol do conhecimento dos "leigos", do conhecimento popular. Para tal processo cooperativo de planejamento é essencial possibilitar uma comunicação recíproca.

Os diagnósticos participativos podem ser descritos como um conjunto de métodos que capacitam pessoas a expressar e analisar a própria realidade e suas condições de vida, propiciando que tais indivíduos decidam quais medidas devem ser tomadas, bem como monitorar e avaliar os resultados. Eles oferecem maneiras de dar voz à população pobre, capacitando-os para expressar e analisar os próprios problemas e prioridades (Chambers 1996).

Particularmente no contexto suburbano e peri-urbano, a conjuntura complexa de interesses nas áreas e nos recursos naturais, assim como a variedade de stakeholders, faz com que se precise tomar medidas de gestão de conflito, para viabilizar uma proteção efetiva de habitats naturais. Como estas áreas são suscetíveis à expansão urbana, muitos atores sociais têm interesses conflitantes com respeito ao uso do solo. Decisões de planejamento são temas que devem ser tratados com cautela.

Apesar do reconhecimento amplo da importância de participação, ainda faltam conceitos claros de como avaliar processos participativos. Especialmente a questão sobre qual grau de delegação de poder decisório é preciso para tornar um processo de planejamento realmente participativo ainda é bastante polêmica.

Um artigo crítico sobre experiências de planejamento participativo escrito por Arnstein (1969), que desencadeou muita discussão a respeito já nos anos setenta, distingue oito graus de participação.

8. transferência de poder para os cidadãos (autogestão)
7. delegação de poder
6. parceria e cooperação
5. mediação de conflitos
4. consulta
3. informação
2. apaziguamento
1. manipulação, desinformação.

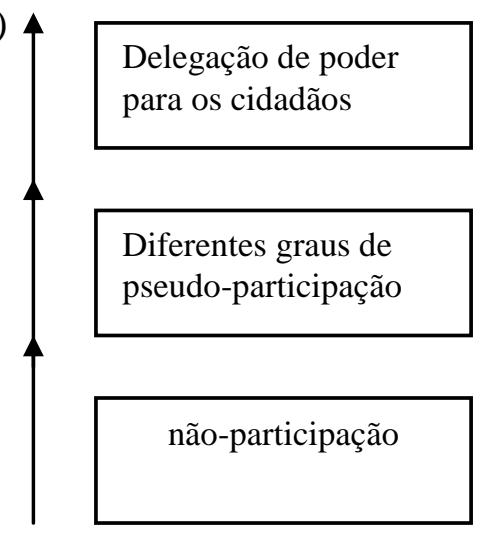

Nos dois primeiros estágios de participação trata-se meramente de uma pseudoparticipação que somente visa a melhorar as relações públicas. Do terceiro até o quinto patamar, segundo Arnstein, ainda não se pode falar de verdadeira participação, pois a comunicação só tem uma direção (de cima para baixo). Não há espaço para negociação e não 
se possibilita um feedback da população. Somente a partir do sexto estágio pode se falar de participação que permita uma relação de parceria entre a população e os tomadores de decisão. No caso extremo do último patamar a população tem a maioria nos processos de decisão.

No entanto, em publicações mais recentes se avaliam processos de participação de forma mais abrangente, não só dependendo do grau de delegação de poder (BorriniFeyerabend 1996; Pimbert \& Pretty 1997). Todos os diferentes níveis de participação podem ser avaliados positivamente, dependendo da finalidade do projeto. A decisão sobre qual nível de participação deve ser atingido depende em grande parte dos objetivos gerais estabelecidos no contexto específico. Segundo Cleaver (1999). pode-se diferenciar entre duas motivações distintas para a implementação de projetos participativos. Uma meta geral pode ser de tornar um projeto mais efetivo através de ferramentas participativas. Neste caso se tem uma visão pragmática de participação, que é um meio para conseguir informações diretas com as pessoas atingidas pelo projeto sobre as demandas reais, por exemplo, com respeito a infraestrutura e serviços públicos. Através de contribuições dos moradores, se espera que o projeto responda melhor à necessidade local. Alem disso, como os atingidos já podem comentar o projeto com antecedência, se evitam reclamações posteriores e, assim, acelera-se o processo de licitação.

Por outro lado, participação também pode ser vista como uma finalidade em si mesma, no sentido de facilitar mudanças sociais e empoderamento de grupos sociais excluídos. Enquanto no entendimento pragmático de participação não visa mudanças políticas e socioeconômicas, o conceito de participação como finalidade em si mesma focaliza na democratização das relações entre instituições governamentais e os cidadãos. Sendo assim, nesta visão de participação se exige também um maior grau de delegação de poder decisório.

Em princípio, os dois conceitos de participação têm sua legitimidade, sob a condição que desde o começo do processo participativo se esclareça qual a finalidade e até que ponto se delegam as competências para os participantes.

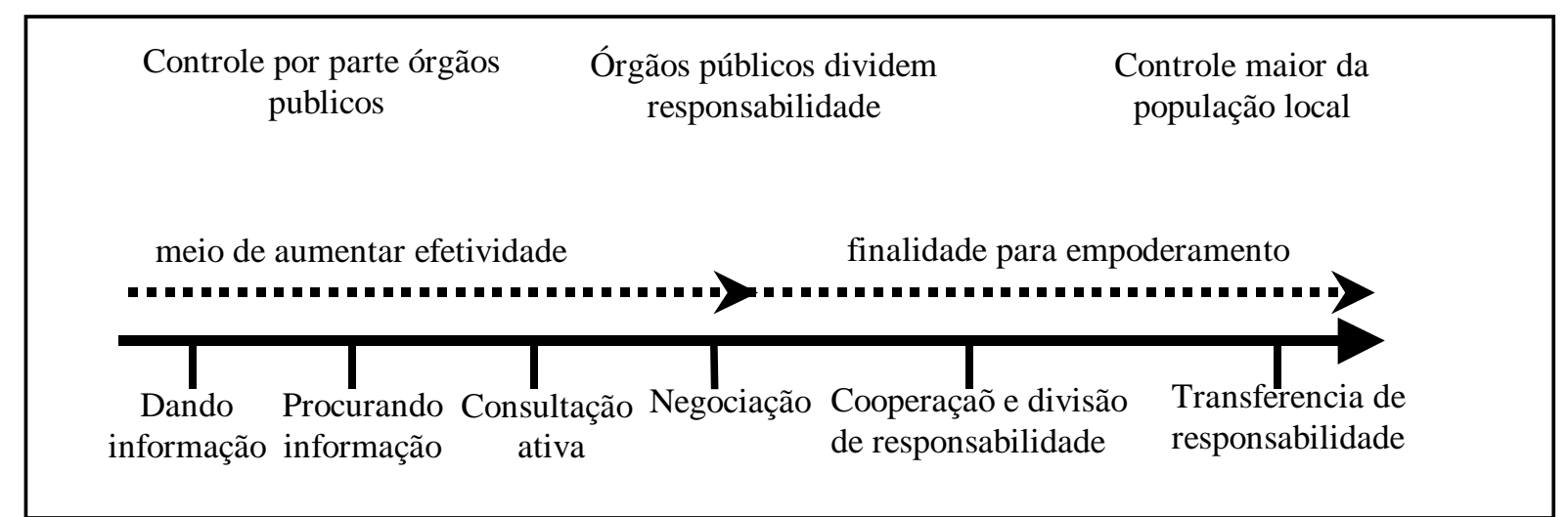

Gráfico 1: Transição entre Diferentes Graus de Participação. (adaptado de Borrini-Feyerabend (1996), Pimbert e Pretty (1997) e Mannigel (2004)).

Por isso, os possíveis critérios para uma avaliação dos processos de participação aqui apresentados não se limitam na avaliação do grau de delegação de poder atingido, mas incluem também a qualidade do processo e os resultados atingidos (vide tabela 1). 


\begin{tabular}{|c|c|c|c|c|c|}
\hline \multicolumn{2}{|c|}{ Condições do processo } & \multicolumn{4}{|c|}{ Critérios ligados aos resultados } \\
\hline Fairness & Competência & Resultado & Aprendizado mútuo & Empoderamento & Eficiência \\
\hline $\begin{array}{l}\text { Representatividade dos } \\
\text { participantes }\end{array}$ & $\begin{array}{l}\text { Competência de } \\
\text { comunicação }\end{array}$ & Consenso atingido & $\begin{array}{l}\text { Técnicos e especialistas } \\
\text { abertos para superar as } \\
\text { diferenças na percepção } \\
\text { dos problemas }\end{array}$ & $\begin{array}{l}\text { Expectativa clara quanto } \\
\text { ao grau de participação a } \\
\text { ser atingido }\end{array}$ & $\begin{array}{l}\text { Decisões coerentes } \\
\text { com as necessidades } \\
\text { locais }\end{array}$ \\
\hline $\begin{array}{l}\text { Transparências dos papeis } \\
\text { dos moderadores e } \\
\text { facilitadores, e dos } \\
\text { participantes e } \\
\text { especialistas. }\end{array}$ & Acesso a informações & $\begin{array}{l}\text { Resultado concreto e } \\
\text { palpável }\end{array}$ & $\begin{array}{l}\text { Desenvolvimento de um } \\
\text { entendimento comum de } \\
\text { sistema e de planejamento }\end{array}$ & $\begin{array}{l}\text { Novos contatos e } \\
\text { cooperação entre os } \\
\text { diferentes grupos, criação } \\
\text { de novas redes. }\end{array}$ & $\begin{array}{l}\text { Implementação } \\
\text { facilitada }\end{array}$ \\
\hline \multirow[t]{2}{*}{$\begin{array}{l}\text { Qualidade do processo de } \\
\text { comunicação (p.ex. regras } \\
\text { claras de negociação) }\end{array}$} & $\begin{array}{l}\text { Conhecimento técnico } \\
\text { não dominou o processo }\end{array}$ & $\begin{array}{l}\text { Comunicação dos } \\
\text { resultados e } \\
\text { conseqüências do } \\
\text { processo }\end{array}$ & & $\begin{array}{l}\text { Autoconfiança aumentada } \\
\text { de grupos excluídos, } \\
\text { maior competência } \\
\text { democrática. }\end{array}$ & $\begin{array}{l}\text { Mobilização de } \\
\text { recursos locais }\end{array}$ \\
\hline & $\begin{array}{l}\text { Consideração do } \\
\text { conhecimento leigo }\end{array}$ & $\begin{array}{l}\text { Eficácia política dos } \\
\text { resultados }\end{array}$ & & $\begin{array}{l}\text { Conscientização, } \\
\text { desenvolvimento de um } \\
\text { senso de comunidade. }\end{array}$ & \\
\hline
\end{tabular}

Tabela 1: Critérios de Avaliação de Processos Participativos 
O debate teórico sobre participação se baseia em grande parte nas teorias de ação comunicativa de Habermas (1981). Daí podem ser deduzidos os critérios de fairness (igualdades das condições para a participação) e competência como critérios de avaliação (Webler 1995). O critério fairness implica sobretudo na questão da representatividade dos participantes relativa à população atingida pelo projeto. Além disso, foi analisado se as regras de discussão e negociação foram claramente definidas e cumpridas. Da mesma maneira foi considerado se os diferentes papéis dentro do processo, como o papel do moderador e facilitador assim como dos especialistas consultados foram respeitados e transparentes. Com respeito à competência foi observado se houve comunicação adequada para igualar as assimetrias de conhecimentos entre os participantes e se o acesso às informações necessárias foi suficiente. É fundamental avaliar se foi transmitido e traduzido o conhecimento técnico e ao mesmo tempo considerar o conhecimento leigo.

Porém, segundo Holmes e Scoones (2000) não é suficiente só analisar os processos, é fundamental analisar também os resultados concretos de um projeto participativo. Neste sentido Oels (2004) e Abers (2000) fornecem alguns conceitos teóricos para avaliação. Primeiro deve ser analisado se houve uma decisão de consenso e se o resultado ficou palpável para os participantes. Ainda é importante verificar se esse resultado foi suficientemente divulgado além do projeto e se houve realmente repercussão política nas instâncias relevantes ou se permaneceu em uma discussão isolada, alheia, da realidade política local.

Um outro critério importante consiste na avaliação dos processos de aprendizagem dentro do processo participativo. Neste sentido é relevante perceber, também, se os especialistas e técnicos conseguiram aprender com os participantes e se foi estabelecida uma percepção comum entre os moradores, os diferentes grupos sociais envolvidos e os técnicos e quais os problemas prioritários a serem enfrentados.

Com o critério de empoderamento se resume a questão se houve através do projeto participativo um fortalecimento da auto-estima e a competência democrática dos atores sociais que anterior ao projeto estavam excluídos dos processos políticos locais. Avalia-se, o engajamento dos grupos sociais pouco organizados no processo participativo, se esses grupos tiveram a oportunidade de influenciar o planejamento e se foram capacitados a defender os próprios interesses. É importante verificar se os participantes aumentaram sua consciência política e através da experiência coletiva ganharam confiança nas próprias competências como atores políticos e desenvolveram um senso comum com respeito aos interesses coletivos.

Com o critério da eficiência se procura avaliar se as decisões tomadas correspondem melhor às necessidades locais, incluindo informações da população diretamente atingida. Além disso, foi analisado se o projeto gerou menos protestos e reclamações em função da maior identificação da população com as decisões tomadas.

\section{Estudo de Caso: instrumentos participativos em abordagens de planejamento cooperativo}

O projeto analisado no estudo de caso por um período de dois anos foi iniciado pela Secretaria de Planejamento Municipal de Porto Alegre (SPM) em cooperação com a Secretaria de Meio Ambiente entre outros. Trata-se de um projeto piloto com o título "Projeto Integrado de Desenvolvimento Sustentável da Lomba do Pinheiro" (PMPA 2005). Este projeto é centrado na atualização do plano diretor num bairro periférico em cooperação com a população atingida. O objetivo é delimitar as áreas que são aptas para ocupação urbana e definir onde a proteção da vegetação natural é prioridade.

Semelhante às técnicas de manejo cooperativo discutidas anteriormente, a idéia do planejamento participativo ou cooperativo visa informar e envolver a população no Métodos Participativos no Planejamento Ambiental no Contexto de Ocupações Informais... 
planejamento e na tomada de decisão, mas com um escopo temático maior do que o anterior. Os problemas ambientais nas áreas periféricas, como a Lomba do Pinheiro, são estreitamente ligados aos processos de exclusão social que obrigam as pessoas a utilizarem áreas não apropriadas para ocupação urbana. Por essa razão, uma abordagem integrada frente aos problemas urbano-ambientais incluindo medidas sociais, econômicas e ambientais é crucial. No projeto analisado, o instrumento central para envolver a comunidade local no processo de tomada de decisão foi um diagnóstico participativo.

Entre os instrumentos participativos aplicados neste projeto de planejamento cooperativo, os mais bem-sucedidos foram exercícios de mapeamento coletivos e a realização de entrevistas semi-estruturadas pelos residentes locais para identificar os mais importantes problemas sociais, econômicos e ambientais no bairro. Utilizando estes instrumentos participativos, uma visão comum da degradação ambiental vinculada aos déficits de infraestrutura urbana e também a comportamentos pessoais, pôde ser alcançada entre os participantes.

\section{Resultados e conclusões}

Aplicando os critérios de avaliação acima mencionados no projeto do estudo de caso se chegou às seguintes conclusões:

No que diz respeito à igualdade das condições de participação se teve dificuldade em garantir a representatividade ampla dos moradores de todo o bairro. Isto porque as lideranças que já eram muito articuladas dominaram as reuniões e ficaram ainda mais fortalecidas. As atividades e as responsabilidades dentro do projeto se concentraram em poucas pessoas. Não se conseguiu envolver, suficientemente, novos atores, nem mesmo aqueles que ainda eram ativos em associações de bairro ou movimentos sociais. Por outro lado, a presença massiva de associações de moradores significou também uma vantagem para o projeto em termos de força de organização e mobilização. Ao mesmo tempo os movimentos mais combativos da região temeram ser cooptados através do projeto participativo iniciado pela secretaria de planejamento.

$\mathrm{Da}$ análise das entrevistas se concluiu que a abordagem participativa representa um avanço significativo com respeito à aprendizagem dos participantes, uma vez que se conseguiu construir um entendimento comum dos problemas locais entre os moradores e os funcionários públicos. Estes últimos, sobretudo, ganharam com isso uma visão realista dos problemas das ocupações informais através do contato direto e contínuo com os moradores.

Por outro lado, a falta de integração dos resultados do processo participativo na atuação das diferentes secretarias na região restringiu significativamente a eficácia do projeto. Existe um abismo entre o processo participativo e os processos decisórios das secretarias setoriais, sendo esta falta de integração institucional uma das principais limitações identificadas neste estudo de caso.

Além disso, um dilema fundamental de tais processos de planejamento, num contexto de urbanização acelerado, é o fato de não se poder interferir nas causas desta expansão urbana informal. Não se consegue modificar a pressão dos novos ocupantes que se mudam para esta região. Processos cooperativos não conseguem compensar os déficits institucionais. Mesmo os moradores, através do projeto participativo, terem sido sensibilizados para as questões ambientais no bairro e chegarem a um consenso sobre as ações necessárias, em muitos aspectos as ações concretas esbarraram nas contradições institucionais das secretarias responsáveis. Por isso pode se concluir que além da democratização do planejamento urbano, é necessário um fortalecimento das instituições locais, possibilitando a implementação de medidas preventivas de política urbana. Não se deve instrumentalizar um processo participativo para contornar as contradições da gestão local, instigando pressão da população 
a respeito de decisões que dentro da administração geram conflitos (por exemplo, no caso de incoerência entre a legislação ambiental e as normas urbanísticas). Porque, assim, corre-se o risco de os resultados do processo participativo serem barrados por parte do governo local.

Apesar disso, os dados das entrevistas sustentam que um processo participativo pode levar a uma dinâmica própria. $\mathrm{O}$ fortalecimento da auto-estima dos participantes como atores políticos pode, a longo prazo, levar a uma melhoria da qualidade ambiental urbana. 'Pois desta maneira, os grupos mais atingidos pela degradação ambiental conseguem reivindicar o atendimento de suas demandas pelo poder público.

Em geral, é preciso ter cautela para não simplificar a participação da população como panacéia para a gestão ambiental. Uma mudança de procedimento "de cima para baixo" para abordagens mais participativas não significa automaticamente uma implementação mais rápida de medidas de conservação ou planejamento ambiental. Muito pelo contrário, processos colaborativos que buscam um consenso, geralmente, são muito lentos. Porém, experiências com participação em processos de planejamento documentado internacionalmente, apontam que decisões tomadas com base em cooperação sejam mais sustentáveis. Mas, ainda faltam estudos de longo prazo para provar isto. Certamente Porto Alegre com sua longa tradição em participação da população nos processos de decisão, sua acumulação de capacidades participativas entre os habitantes e o importante capital social relativo aos movimentos sociais, é um solo fértil para o futuro desenvolvimento de técnicas participativas na área de planejamento ambiental.

\section{Referências Bibliográficas}

ABERS, R. N. Inventing local democracy: Grassroots politics in Brazil. London: Lynne Rienner Publishers, 2000. 267 p.

BAUD, I. S. A.; HORDIJK, M. Ressource flows and urban governance: Approaching environmental transition in cities and their hinterland. In: BAUD, I. S. A.; POST, J. (Ed.) Realigning actors in an urbanizing world: Governance and Institutions from a development perspective. Aldershot: Ashgate, 2002. p. 313-328.

BAUD, I. S. A.; POST, J. (Ed.) Realigning actors in an urbanizing world: Governance and institutions from a development perspective. Aldershot: Ashgate, 2002. 425 p.

BORRINI-FEYERABEND, G. Collaborative management of protected areas: Tailoring the approach to the context. Gland, Switzerland: IUCN, The World Conservation Union, 1996 Social Policy Unit. 86 p.

CHAMBERS, R. J. H. Relaxed and participatory appraisal: Notes on practical approaches and methods. In: BLISS, F.; NEUMANN, S. (Ed.): Ethnologische Beiträge zur

Entwicklungspolitik. Bonn: Horlemann-Verlag, 1996. p. 74-90.

CLEAVER, P. Paradoxes of participation: Questioning participatory approaches to development. Journal of International Development, v. 11, n.5, p. 597-612, 1999.

FREY, K. Deliberative Demokratie und städtische Nachhaltigkeit: Konzeptionelle Überlegungen und Erfahrungen aus der brasilianischen Kommunalpolitik. LateinamerikaAnalysen, v. 1, n.1, p. 83-113, 2002. 
GAVENTA, J. ; VALDERRAMA, C. Participation, citizenship and local governance. Background note prepared for workshop on 'Strengthening participation in local governance'. 1999. Disponível em:

<http://www.ids.ac.uk/ids/particip/research/citizen/gavval.pdf $>$. Acesso em: 01 mar. 2006.

HABERMAS, J. Theorie des kommunikativen Handelns. Suhrkamp: Frankfurt, 1981. 640 p.

HOLMES, T.; SCOONES, I. Participatory environmental policy processes: experiences from North and South. Brighton, UK: Institute of Development Studies (IDS), 2000. 20 p.

MAHANTY, S.; RUSSEL, D. High Stakes: Lessons from Stakeholder Groups in the Biodiversity Conservation Network. Society and Natural Resources, v. 15, p. 179-188, set. 2002.

MANNIGEL, E. Integrating parks and neighbors: Participation and protected areas in Minas Gerais, Brazil. Eschborn: Deutsche Gesellschaft für Technische Zusammenarbeit (GTZ), 2004. 254 p.

McNEELY, J. A. (Ed.): Expanding partnership in conservation. Washington D.C.: Island Press, 1995.318 p.

OELS, A. Evaluating stakeholder participation in the transition to sustainable development: Methodology, case studies, policy implications. Münster: Lit Verlag, 2003. $251 \mathrm{p}$.

PIMBERT, M. P.; PRETTY, J. N. Parks, people and professionals: Putting "participation" into protected area management. In: GHIMIRE, K. B.; PIMBERT, M. P. (Ed.) Social change and conservation: Environmental politics and impacts of national parks and protected areas. London: Earthscan Publications Ltd., 1997. p. 297-330.

SAULE Jr., N; VELASCO, A. M.; ARASHIRO, Z. LogoLink Latin America: Legal and policy frameworks for citizen participation. LogoLink São Paulo. 2002. Disponível em: <http://www.ids.ac.uk/logolink/resources/downloads/regionalreports/RegionalReportLatinAm erica\%20final.pdf>. Acesso em: 01 mar. 2006.

STOLL-KLEEMANN, S.; O'RIORDAN, T. From participation to partnership in biodiversity protection: Experience from Germany and South Africa. Society and Natural Resources, v. 15, p. 161-177, set. 2002.

WEBLER, T. Right discourse in citizen participation: an evaluative yardstick. In: RENN, O.; WEBLER, T.; WIEDEMANN, P. (Ed.): Fairness and competence in citizen participation: Evaluating models for environmental discourse. London: Kluwer Academic Publishers, 1995. p. 35-86.

\footnotetext{
${ }^{1}$ Este trabalho faz parte da tese de doutorado da autora desenvolvido no contexto do projeto de cooperação entre a UFRGS e a Technische Universität München, financiado pela CAPES e pelo DAAD, sob o título "Proteção e manejo de áreas naturais na região de Porto Alegre, RS, Brasil, com base no estudo de padrões e dinâmica da vegetação". A tese completa pode ser acesada em <http://mediatum.ub.tum.de/mediatum/>.
} 